\title{
Phylogenomic Insights into Distribution and Adaptation of Bdellovibrionota in Marine Waters
}

\author{
Qing-Mei Li ${ }^{1,2}$, Ying-Li Zhou ${ }^{1,2}$, Zhan-Fei Wei ${ }^{1,2}$ and Yong Wang ${ }^{1, *}$ \\ 1 Institute of Deep Sea Science and Engineering, Chinese Academy of Sciences, Sanya 572000, China; \\ liqm@idsse.ac.cn (Q.-M.L.); zhouyl@idsse.ac.cn (Y.-L.Z.); weizf@idsse.ac.cn (Z.-F.W.) \\ 2 University of Chinese Academy of Sciences, Beijing 100049, China \\ * Correspondence: wangy@idsse.ac.cn
}

Citation: Li, Q.-M.; Zhou, Y.-L.; Wei, Z.-F.; Wang, Y. Phylogenomic Insights into Distribution and Adaptation of Bdellovibrionota in Marine Waters.

Microorganisms 2021, 9, 757.

https://doi.org/10.3390/

microorganisms 9040757

Academic Editor: Ulrich (Uli) Stingl

Received: 22 February 2021

Accepted: 1 April 2021

Published: 3 April 2021

Publisher's Note: MDPI stays neutral with regard to jurisdictional claims in published maps and institutional affiliations.

Copyright: (c) 2021 by the authors. Licensee MDPI, Basel, Switzerland. This article is an open access article distributed under the terms and conditions of the Creative Commons Attribution (CC BY) license (https:// creativecommons.org/licenses/by/ $4.0 /)$.

\begin{abstract}
Bdellovibrionota is composed of obligate predators that can consume some Gram-negative bacteria inhabiting various environments. However, whether genomic traits influence their distribution and marine adaptation remains to be answered. In this study, we performed phylogenomics and comparative genomics studies using 132 Bdellovibrionota genomes along with five metagenomeassembled genomes (MAGs) from deep sea zones. Four phylogenetic groups, Oligoflexia, Bdellogroup1, Bdello-group2 and Bacteriovoracia, were revealed by constructing a phylogenetic tree, of which $53.84 \%$ of Bdello-group 2 and $48.94 \%$ of Bacteriovoracia were derived from the ocean. Bacteriovoracia was more prevalent in deep sea zones, whereas Bdello-group2 was largely distributed in the epipelagic zone. Metabolic reconstruction indicated that genes involved in chemotaxis, flagellar (mobility), type II secretion system, ATP-binding cassette (ABC) transporters and penicillin-binding protein were necessary for the predatory lifestyle of Bdellovibrionota. Genes involved in glycerol metabolism, hydrogen peroxide $\left(\mathrm{H}_{2} \mathrm{O}_{2}\right)$ degradation, cell wall recycling and peptide utilization were ubiquitously present in Bdellovibrionota genomes. Comparative genomics between marine and non-marine Bdellovibrionota demonstrated that betaine as an osmoprotectant is probably widely used by marine Bdellovibrionota, and all the marine genomes have a number of genes for adaptation to marine environments. The genes encoding chitinase and chitin-binding protein were identified for the first time in Oligoflexia, which implied that Oligoflexia may prey on a wider spectrum of microbes. This study expands our knowledge on adaption strategies of Bdellovibrionota inhabiting deep seas and the potential usage of Oligoflexia for biological control.
\end{abstract}

Keywords: bdellovibrionota; deep sea; bacterial predator; phylogeny; metabolism

\section{Introduction}

Bdellovibrionota, well known as Bdellovibrio and like organisms (BALOs), are Gramnegative bacterial predators and are isolated from various environments. Bdellovibrionota are small vibrio-shaped bacteria with a polar flagellum [1]. In 1965, the first free-living BALO, Bdellovibrio bacteriovorus, was reported, which led to a discovery that predation process of Bdellovibrionota includes two steps, (1) attachment and degradation of prey cell wall with glycanases and (2) digestion of prey cellular components with exoenzyme [2]. Using Escherichia coli as a prey model, experimental results showed that Bdellovibrionota could penetrate the host cell and then transform into a bdelloplast before being released from the host cell [3]. In 1979, Bdellovibrionota was found to be an agent against pathogens [4], indicating the usage of Bdellovibrionota as a new approach to biocontrol that fights against bacterial infections, particularly when multidrug-resistant (MDR) bacteria are increasingly concerned globally [5]. MDR bacterial infections have been successfully treated with the assistance of bacterial predation by Bdellovibrionota [6]. The prey spectrum of Bdellovibrionota has recently expanded to Gram-positive pathogenic bacteria such as Enterococcus [7]. 
The current Bdellovibrionota phylum consists of several classes according to the Genome Taxonomy Database (GTDB, Release 89) [8], such as Bacteriovoracia, Bdellovibrionota, Oligoflexia and others without a taxonomic assignment. They are inhabitants that can be identified in various environments, such as soil, freshwater (river, lake and spring), ocean, wastewater treatment bioreactor and sewage [9-12]. In different ecological niches, Bdellovibrionota could live with a prey-dependent or prey-independent lifestyle [11]. This provides a clue to the metabolic flexibility of Bdellovibrionota, as well as to different predatory mechanisms when invading periplasmic space or attaching to the external surface of prey bacterial cell $[1,13]$. As bacterial predators distributed in a wide variety of niches with diversified predatory approaches, ecological roles of Bdellovibrionota were probably underestimated.

The ocean is probably the biggest reservoir of bacteria. So far the reported obligatory predator bacteria mainly include Micavibrio (a genus of $\alpha$-proteobacteria) and five families belonging to $\delta$-proteobacteria [14]. Proteobacteria is a super phylum that constitutes Gram-negative bacteria and dominates the microbial communities in dark deep-sea zones [15]. Experiments had exhibited that Halobacteriovorax, affiliated with one group of Bdellovibrionota, could predate deep-sea bacterium Vibrio parahaemolyticus (Gram-negative bacterium) [16]. In nutrient-poor deep sea, Gram-negative bacteria may meet difficulties in synthesis biopolymers of key cellular structural components, such as peptidoglycan. Therefore, Bdellovibrionota can probably prey on more Gram-negative bacteria, which likely occurs ubiquitously in deep-sea environments [17]. Under oligotrophic deep-sea environment, the competition for nutrient among microorganisms was constantly intensive [18]. The adaptation strategy of Bdellovibrionota in marine environment is still an unresolved issue.

In this study, available Bdellovibrionota genomes were collected for phylogenomic analysis along with five representative Bdellovibrionota genomes binned from the marine metagenomes. The environmental sources of the genomes indicated that two subclades (Bacteriovoracia and Bdello-group2) were mostly present in the marine environment. Bacteriovoracia were increasingly abundant in deeper ocean, while Bdello-group2 prefers to inhabit the epipelagic zone. Comparative genomics demonstrated that marine Bdellovibrionota species evolved to have genes involved in osmolyte metabolism. Oligoflexia may be a potential biocontrol agent of pathogens beyond bacteria since we discovered genes encoding chitin-binding protein and chitinase.

\section{Methods}

\subsection{Genome Collection from Public Databases and Quality Control}

We recruited 148 Bdellovibrionota genomes from the GTDB database [8] (data collected until July 2020). Eight genomes for model Bdellovibrionota were downloaded from the national center for biotechnology information (NCBI). All the 156 genomes (Table S1) were reclassified with GTDB-tk (v.1.0.1) [8]. Quality control of all the genomes was conducted using CheckM (v.1.1.2) [19]. Medium- and high-quality genomes (Table S2) used for further analysis were selected with the following standards: (1) completeness score was more than $70 \%$; (2) contamination rate was less than $10 \%$; (3) the number of conserved proteins derived from CheckM program was at least 22. The sources of the genomes and metagenomes were obtained from the NCBI Biosample and Bioproject.

\subsection{Marine Water Samples Collection, DNA Extraction and Sequencing}

About $20 \mathrm{~L}$ marine water samples were in situ filtered from the Mariana Trench during $R / V$ TS09 by an in situ microbial filtration and fixation (ISMIFF) apparatus and sampling procedure had been described in our previous report [20]. 20L water samples were also collected at different depths by Niskin bottles from the South China Sea during an $R / V$ Tan Kah Kee cruise and $R / V$ Haigong623 equipped with the remotely operated vehicle (ROV) Haixing6000 (Table 1). We used $0.22 \mu \mathrm{m}$ polycarbonate membranes (Merck Millipore, Bedford, MA, USA) for microbial filtration and were then frozen at $-80{ }^{\circ} \mathrm{C}$ 
degree immediately until use. The polycarbonate membranes were cut into small pieces for DNA extraction using MO BIO Power Soil DNA Isolation Kit (MoBio, Carlsbad, CA, USA) according to the manufacturer's instruction. The quality and quantity of the DNA extraction were evaluated by $1 \%$ agarose gel electrophoresis and Qubit 3.10 Fluorometer (Invitrogen, Life, Carlsbad, CA, USA). The good-quality DNA was first sheared randomly to fragments of around $500 \mathrm{bp}$ by a focused ultrasonicattor (Covaris M220) and used for metagenomic library preparation with TruSeq ${ }^{\circledR}$ Nano DNA LT Sample Prep Kit (Illumina, San Diego, CA, USA). The high-throughput sequencing was performed on an Illumina Miseq platform $(2 \times 300 \mathrm{bp})$.

Table 1. Information of metagenome-assembled genomes (MAGs) of marine Bdellovibrionota.

\begin{tabular}{cccccc}
\hline Bin_id & K1B34 & M27B12 & M27B96 & R3B4 & R4B59 \\
\hline Depth (m) & 1000 & $3000 ~ 5000$ & $3000 \sim 5000$ & 1646 & 5992 \\
Sampling site & $116.47^{\circ}$ & $142.01^{\circ}$ & $142.01^{\circ}$ & $120.03^{\circ}$ & $123.31^{\circ}$ \\
(E; N) & $18.01^{\circ}$ & $11.16^{\circ}$ & $11.16^{\circ}$ & $21.87^{\circ}$ & $22.82^{\circ}$ \\
Com. (\%) & 75.16 & 98.21 & 80.15 & 81.83 & 71.94 \\
Con. (\%) & 0.00 & 0.89 & 2.98 & 2.52 & 0.89 \\
N50 (bp) & 6396 & 295,316 & 5991 & 7831 & 3968 \\
No. contigs & 597 & 24 & 684 & 923 & 570 \\
Genome size (bp) & $3,229,602$ & $4,849,992$ & $3,554,382$ & $5,883,831$ & $2,188,444$ \\
No. CDSs & 3741 & 4431 & 4172 & 5667 & 2566 \\
\hline
\end{tabular}

$\mathrm{R}$ and $\mathrm{K}$ in Bin_id represent the South China Sea; M denotes the Mariana Trench. Com., completeness; Con., contamination; N50, the shortest contig length required to cover 50\% of the genome. CDS, coding sequence.

\subsection{Raw Data Processing, de Novo Assembly and Metagenomes Binning}

The quality of metagenome raw data was assessed by FastQC (v.0.11.8) [21] . After Fastp (v0.20.0) [22] treatment, repeated sequences produced by the sequencing platform were removed by Fastuniq [23] and then the clean reads were assembled with MEGAHIT (v.1.2.5-beta) [24]. The contigs $>2000 \mathrm{bp}$ were selected for genome binning with MetaWRAP (v1.2) (models including metabat2, maxbin2 and concoct) [25]. The MAGs were then taxonomically classified by GTDB-tk classifier [8] and five Bdellovibrionota MAGs were selected by the cut-off described above ( $>70 \%$ completeness and $<10 \%$ contamination).

\subsection{Calculation of Bdellovibrionota Relative Abundance in Deep Sea}

We extracted 16S rRNA sequences of Bdellovibrionota genomes and MAGs by using rRNA_hmm_fs_wst (v.0) [26] and used to create a 16S rRNA database. The Bdellovibrionota 16S rRNA metagenomic Illumina tags (miTags) in Tara Ocean [27] and Mariana marine water metagenomes [28,29] (Table S3) were identified by BLASTN [30] (v.2.9.0) (E-value, $1 \times 10^{-5}$ ) against the $16 \mathrm{~S}$ rRNA sequence database of Bdellovibrionota. Only the $16 \mathrm{~S}$ miTags longer than $100 \mathrm{bp}$ and $>97 \%$ identity to a reference in the database were selected for further calculation of their relative abundance in the marine samples. The Tara Ocean data were downloaded (http:/ / ocean-microbiome.embl.de/data/miTAG.taxonomic.profiles. release.tsv.gz accessed on 22 February 2021). A $t$-test was performed for significance analysis.

\subsection{Genome Annotation and Metabolic Reconstruction}

Open reading frames (ORFs) were predicted by Prodigal (v.2.6.3) [31] and were then annotated by Kofamscan [32] (v.1.0.0; -f mapper) against the Kyoto Encyclopedia of Genes and Genomes (KEGG) database [33] (Release 92) and by BLASTP (v.2.9.0) [34] against Cluster of Orthologous Groups of proteins (COG) database (COG_2019_v11.0) [35]. Carbohydrate related enzymes were searched with hmmscan (v. 3.2.1) [36] against the Carbohydrate Active EnZyme (CAZy) database (dbCAN-HMMdb-V7) [37]. Peptidases were identified by BLASTP against the MEROPS database [38] (pepunit.lib; -id 50; -e 1e $\mathrm{e}^{-10}$ ). Biosynthetic gene clusters of Bdellovibrionota were identified by using antiSMASH (v.4.2.0) [39] using default parameters and further confirmed BLASTP against MIBIG data (v.2.0) [40] as de- 
scribed elsewhere [41]. A Wilcoxon test in R package was conducted to identify the genes significantly different in abundance between different groups.

\subsection{Phylogenetic Analysis of Conserved Proteins and 16S rRNA Genes}

Average nucleotide identity (ANI) analysis was executed by the pyani (v.0.2.9) (software available from https://github.com/widdowquinn/pyani/releases; released on 21 May 2019) to remove redundant genomes with $\geq 98.5 \%$ identity [42]. A total of 86 nonredundant Bdellovibrionota genomes were used for phylogenetic analysis (Table S2). The conserved proteins of genomes were aligned using hmmerAlign.py (called by CheckM). The alignment of 43 concatenated conserved proteins (Table S2) was used for reconstruction of phylogenomic tree with RAxML [43] (v.8.2.12; -\# 1000; -m PROTGAMMALG) after optimization with trimAl [44] (v.1.4). All the 16S rRNA sequences extracted by rRNA_hmm [26] were treated with CD-HIT [45] (v.4.8.1; -c 0.97; -n 10; -G 1; -M 10000) to remove the same species. Two 16S rRNA sequences of E. coli were added as an out-group. All $16 \mathrm{~S}$ rRNA sequences were aligned with MAFFT [46] (v.7.407) and optimized with trimAl. RAxML (v. 8.2.12; GTRCAT model) was used to build a $16 \mathrm{~S}$ rRNA phylogenetic tree with bootstrap values based on 1000 replicates. All phylogenetic trees were visualized with iTOL [47].

\subsection{Availability of Data and Materials}

The genomes from public databases were listed in Table $\mathrm{S} 1$ and the MAGs assembled in this study can be obtained from NCBI Bioproject (PRJNA668648).

\section{Results}

\subsection{Phylogenomics of Bdellovibrionota}

We recruited 156 genomes of Bdellovibrionota from the GTDB and NCBI databases. Five MAGs that represent deep-sea Bdellovibrionota were retrieved from marine water samples of the Mariana Trench, the Bashi Strait and the South China Sea with depths ranging from $1646 \mathrm{~m}$ to $5992 \mathrm{~m}$ (Table 1). The five deep-sea MAGs were in the size range of 2.19 5.88 Mbp with more than $70 \%$ completeness and less than $3 \%$ contamination (Table 1).

Construction of a phylogenomic tree using 43 conserved proteins of 86 non-redundant medium- and high-quality genomes (Table S2) displayed four phylogenetic groups (subclades), which were then named as 'Bacteriovoracia', 'Oligoflexia', 'Bdello-group1' and 'Bdello-group2' (Figure 1A,B). The phylogenetic relationships between the groups were consistent with those based on $16 \mathrm{~S}$ rRNA genes (Figure S1). The five deep-sea MAGs were distributed into three Bdellovibrionota groups except for the Bdello-group1 (Figure 1A,B). The available isolation sources of the samples and genomes were collected and summarized. These genomes were mainly obtained from marine water, subsurface sediment and bioreactor sludge, waste water and ground water (Figure 1C). Bdello-group2 and Oligoflexia were found in more diversified environments (Figure 1C). Marine and ground water were the most common sources for Bdellovibrionota, which coincides with their preference for an environment with low viscosity [48]. About $43.40 \%$ of Bacteriovoracia and $46.81 \%$ of Bdello-group2 genomes were derived from marine waters (Figure 1C), perhaps implying their important role in oceans. The wide spread of Bdellovibrionota may be attributable to a two-phase lifestyle and quick response to the transformation between the phases [49].

Among the four groups, the size of Oligoflexia genomes varies considerably (Figure 1D). This is true for their genomic GC contents ranging from $32.83 \%$ to $54.35 \%$ (Figure 1E), which might be stemmed from the presence of many copies of transposase genes in their genomes (Figure S2). The average GC content of Bdello-group1 genomes was highest with a mean value more than $50 \%$ (Figure 1E). Note that about $30 \%$ of the Bdello-group1 genomes were obtained from sludge bioreactors (Figure 1C). 
A

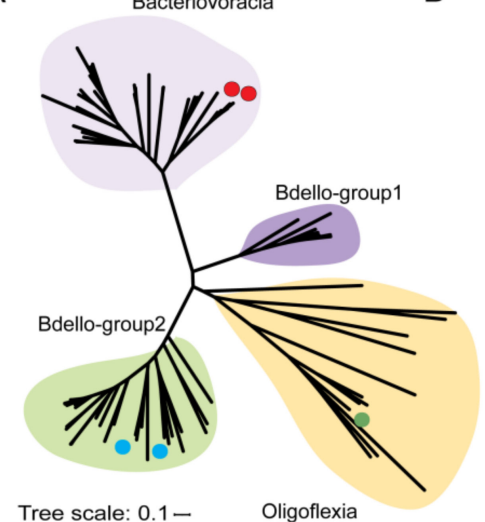

C
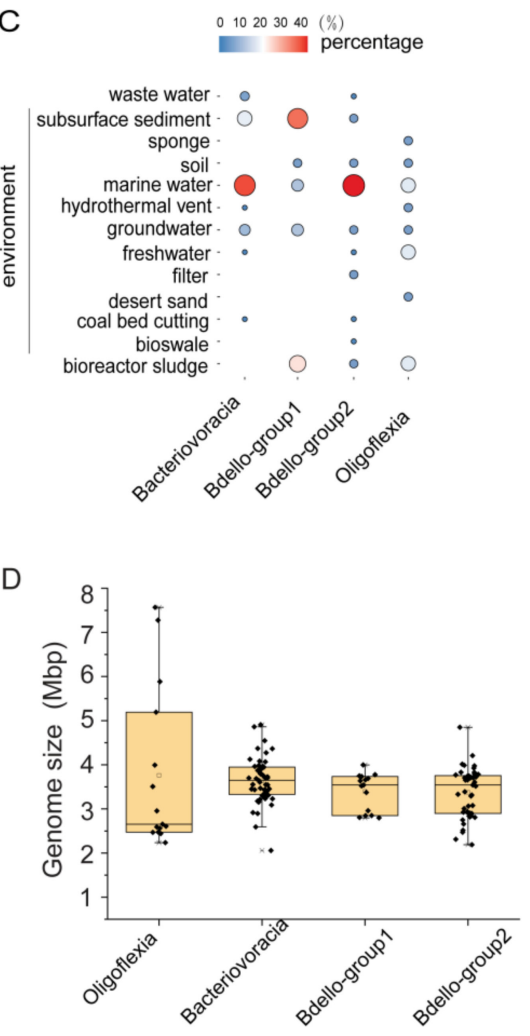

B

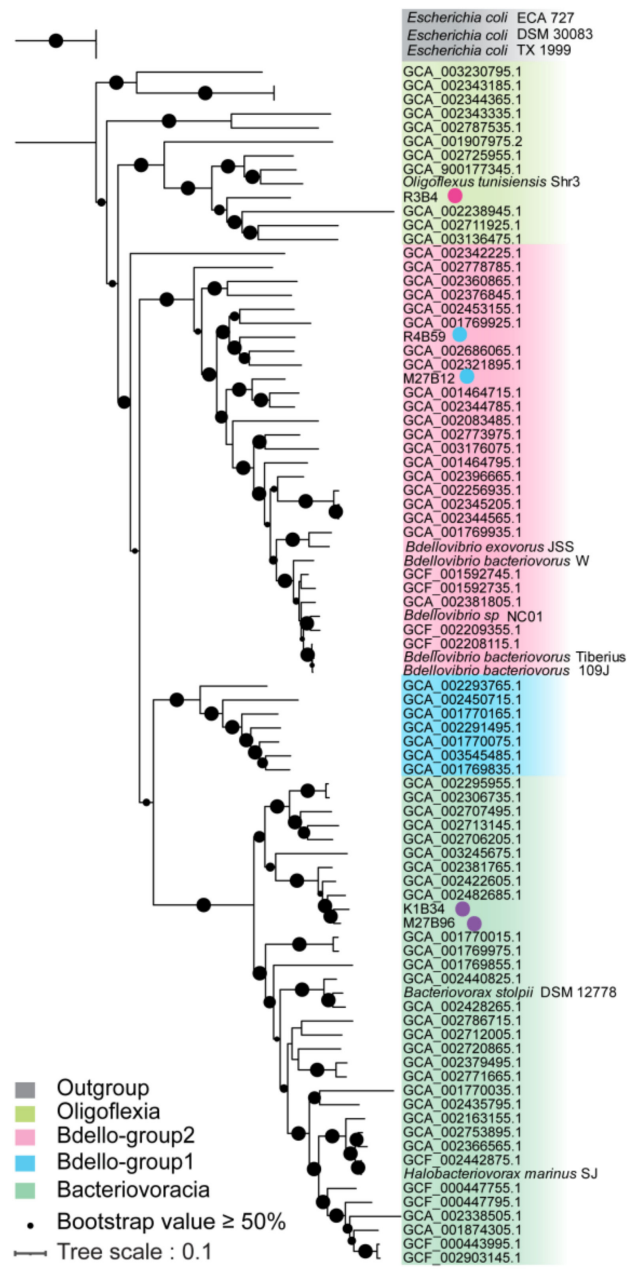

E

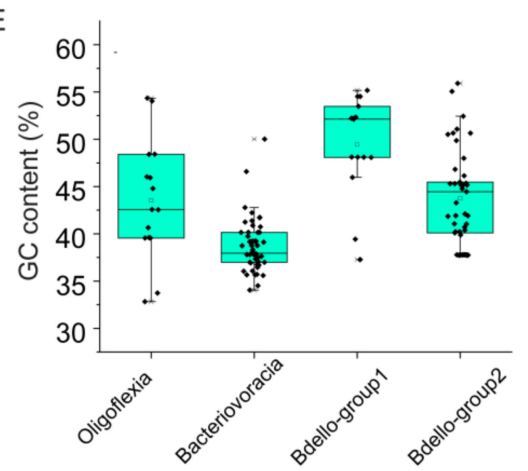

Figure 1. Phylogenomic analysis, distribution and genomic features of Bdellovibrionota. (A) Unrooted maximum-likelihood (ML) phylogenomic tree of Bdellovibrionota. The ML tree was constructed based on 43 concatenated conserved proteins with the PROTGAMMALG model. The MAGs from this study were marked with a dot. (B) Rooted ML phylogenomic tree of Bdellovibrionota. The tree was built up using three E. coli genomes as an outgroup. The genomes with a dot were marine MAGs from this study and the references were shown as their Genome Taxonomy Database (GTDB) accession numbers or species names. (C) Environmental source of Bdellovibrionota genomes. The size and color of dots represent the percentage of the sources in each group. (D) genome size and (E) cytosine and guanine (GC) content of Bdellovibrionota genomes were also plotted.

\subsection{Relative Abundance of Bdellovibrionota in Marine Water Zones}

To examine vertical distribution of the four Bdellovibrionota groups (Figure 1A) in marine water zones, the 16S miTags of the Tara Ocean [27] and Mariana marine water metagenomes $[28,29]$ were used to calculate relative abundance of Bdellovibrionota. Bacte- 
riovoracia and Bdello-group2 were relatively abundant in oceans, compared to the other two groups (Figure 2A). The relative abundance of Bacteriovoracia increased with water depth, whereas a reverse trend was observed for Bdello-group2. Statistical analysis showed that epipelagic layer had significantly more abundant Bdello-group2 than the other deepsea layers, whereas significantly more abundant Bacteriovoracia were distributed in deeper layers ( $t$-test, $p<0.05)$ (Figure 2B). These results strongly indicate that Bacteriovoracia was relatively more prevalent in the deeper marine environment. Conversely, Bdellogroup2 prefers to inhabit the epipelagic zone. Oligoflexia and Bdello-group1 are associated with very low relative abundance in marine environment (Figure 2B). Oligoflexia showed increased tendency with significance between epipelagic and mesopelagic zones ( $t$-test, $p<0.05)$, whereas there was no significance when comparing the epipelagic and deeper layer $(\geq 1000 \mathrm{~m}$ ) (Figure $2 \mathrm{~B})$. Those results showed that vertical distribution pattern of Bdellovibrionota differed between the groups, suggesting considerable differences in their gene profiles.

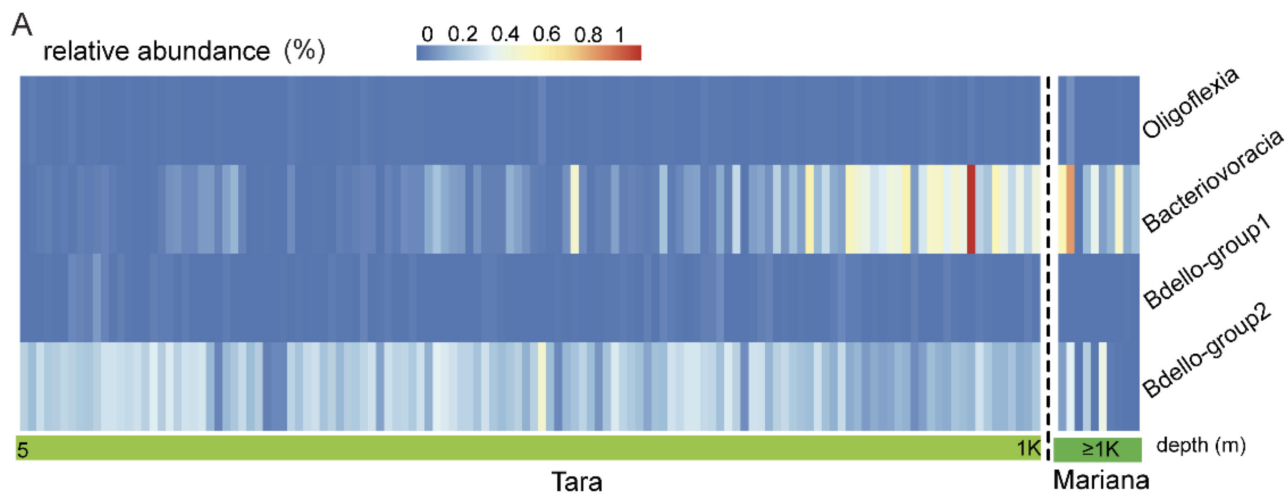

B
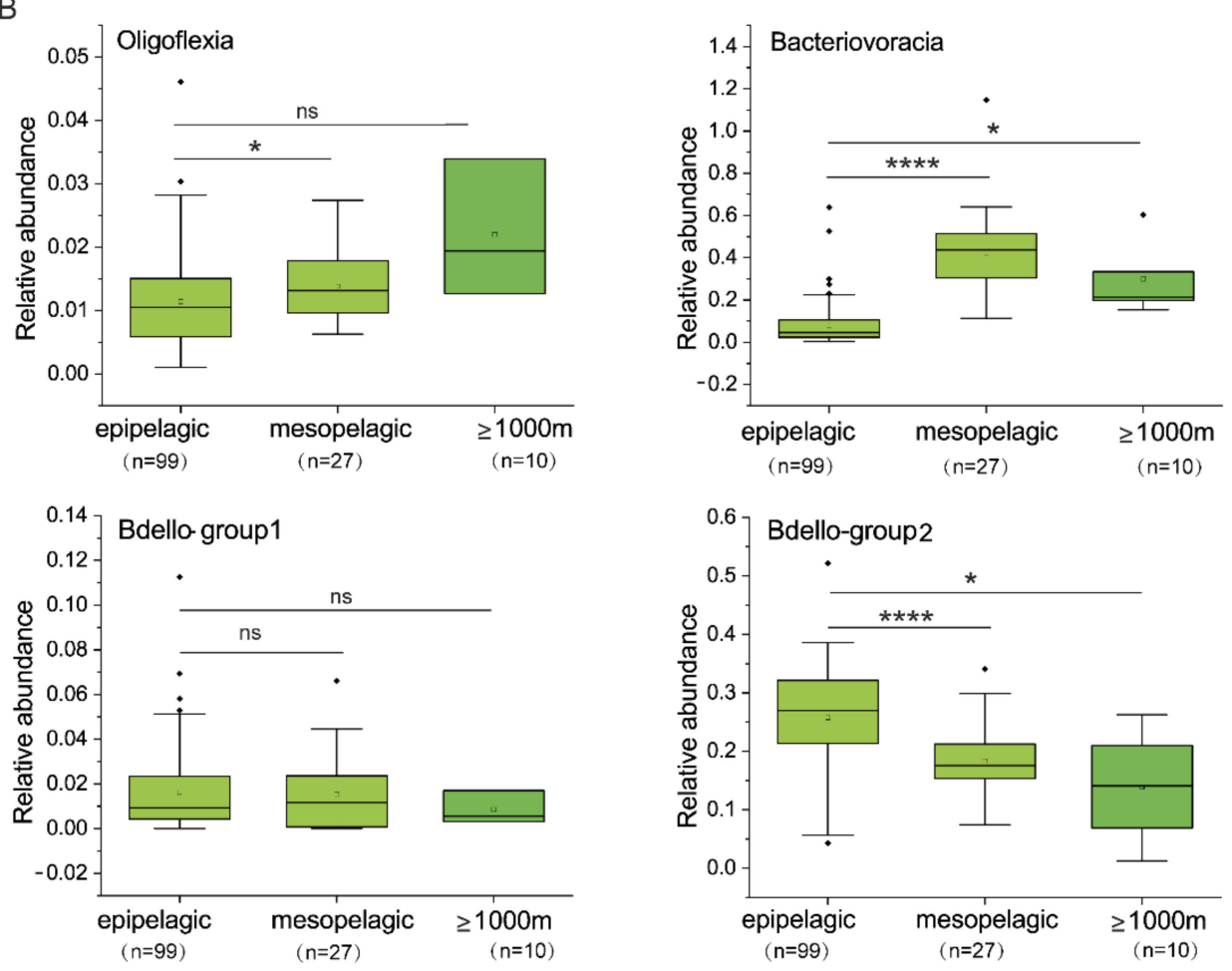

Figure 2. Vertical distribution of Bdellovibrionota in marine waters. (A) Relative abundance of Bdellovibrionota was calculated as percentage of Bdellovibrionota 16S miTags in metagenomes of the Tara Ocean project (depth from $5 \mathrm{~m}$ to $1000 \mathrm{~m}$ ) and the Mariana Trench ( $\geq 1000 \mathrm{~m}$ ) (Table S3) (Gao et al., 2019; Li et al., 2019). (B) Relative abundances of Bdellovibrionota groups in different marine layers were plotted. A $t$-test was performed to compare the relative abundances at different layers. $\left.{ }^{* * * *}, p<0.0001 ;{ }^{*}, p<0.05\right)$. 


\subsection{Metabolic Potentials (Reconstruction) of Bdellovibrionota}

The 80 high-quality ( $>90 \%$ completeness and $<5 \%$ contaminant) genomes from public databases and five deep-sea MAGs binned for this study were used for gene annotation against KEGG [33], COG [35], MEROPS [38] and CAZy databases [37]. Discrepancies of the Bdellovibrionota groups in metabolism and environmental adaptation were detected by comparing the annotation results. When group-specific genes (only present in more than $50 \%$ genomes of one group) were selected from KEGG and COG annotation results, we found that Oligoflexia genomes contained 48 KEGG genes and 34 COGs as groupspecific genes, remarkably more than other groups (Figure 3A). The peptidase-coding genes found in MEROPS annotation were compared, which showed that six peptidase genes were shared by four groups and each group also contained unique peptidases (Figure 3B). Oligoflexia differs from other groups of Bdellovibrionota with higher average number of unique peptidases (Figure 3B), which indicated that Oligoflexia may degrade a wide spectrum of peptides for survival or adaptation [50]. Based on CAZy annotation, Oligoflexia genomes encode more enzymes of glycosyl transferase (GT) families than other groups (Figure 3C). GT enzymes can catalyze the transfer of sugar moieties onto aglycons, which is related to transformation of many natural products [51]. This indicates that Oligoflexia may heavily depend on degradation of carbohydrate from prey bacterial cells and environment. In addition, the secondary metabolite gene clusters encoding nonribosomal peptide synthetases (NRP) and for synthesis of NRP-polyketide, polyketide, polyketide-saccharide, ribosomally synthesized and post-translationally modified peptides (RiPP) and saccharide were present in one or more genomes of each group (Table S4). The results might indicate that Bdellovibrionota are potentially capable of producing secondary metabolite.

A

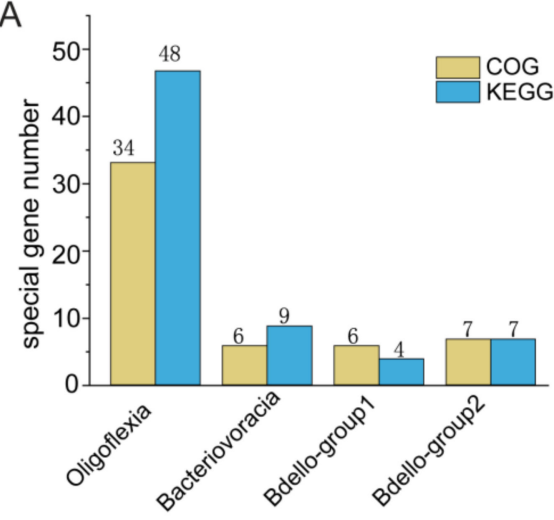

B

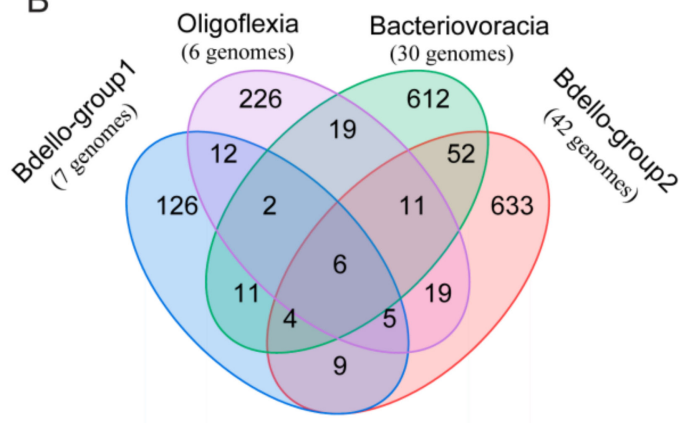

C

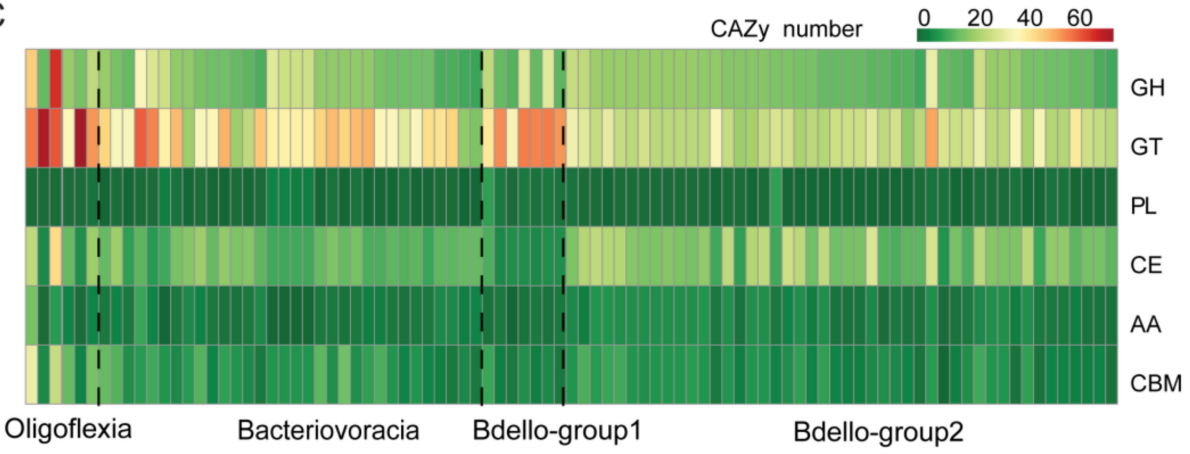

Figure 3. Gene content difference among Bdellovibrionota groups. (A) Number of group-specific Cluster of Orthologous Groups of proteins (COG) and Kyoto Encyclopedia of Genes and Genomes (KEGG) genes. (B) Venn diagram showing groupspecific and shared peptidases of Bdellovibrionota. (C) Heatmap illustrating differences in number of carbohydrate active enzyme (CAZy) classes. GH, glycoside hydrolases; PL, polysaccharide lyases; GT, glycosyl transferases; $\mathrm{CE}$, carbohydrate esterases; CBM, carbohydrate-binding modules; AA, auxiliary activities. 
To disentangle the metabolic and adaptive capacities of Bdellovibrionota, metabolism reconstruction was carried out and presented (Figure 4). If at least $50 \%$ genomes of a group harbor a gene, the group was regarded to have the gene. As bacterial predators, Bdellovibrionota genomes all harbor genes that encode an almost full set of subunits involved in mobility (FlgKGI, FliG/M/N and MotA), chemotaxis (CheY, B, W, A, R and monocyte chemoattractant protein, $\mathrm{MCP}$ ), type II secretion system and some $\mathrm{ABC}$ transporters (Table S5). These chemotactic proteins may work effectively and help Bdellovibrionota to sense abundance of prey bacteria and toxic chemicals [52]. Multicopies of $m c p$ (up to 27 copies) and mot $A$ genes were predicted in an Oligoflexia genome (GCA_001907975.2 or [32] in this study) (Table S6). Artificial mutations of $m o t A$ affected integrality of flagellar [53], which indicated that MotA is important in flagellar assembly. MCP, a methyl accepting chemotaxis protein, was reported to act as an enhancer for predatory ability of Bdellovibrionota [54]. In addition, cheB was predicted in all the groups $(71.42 \%$ of Oligoflexia genomes; all of the Bacteriovoracia genomes; $57.14 \%$ of Bdello-group 1 genomes and $89.13 \%$ of Bdello-group2 genomes) (Table S5). During bacterial rapid adaptation and responding to the local gradients of attractants or repellents, protein $\mathrm{CheB}$, a methylesterase, functions in covalent modification of membrane receptors [55]. A gene encoding a methyltransferase CheR is present in all the Bdellovibrionota groups (Table S5) [56]. Methylation enhances clockwise signals of the motors, while demethylation attenuates them by means of a feedback loop that is managed by $\mathrm{CheB}$ and CheR with respect to methylation rate of receptors [57]. This is the nature of motor transition between clockwise and counterclockwise to respond to the changes of environmental factors. Bdellovibrionota may hunt other bacteria with assistance of methylated modification related chemotaxis proteins ( $\mathrm{CheB}$, CheR and MCP) for precise control of bacterial motility.

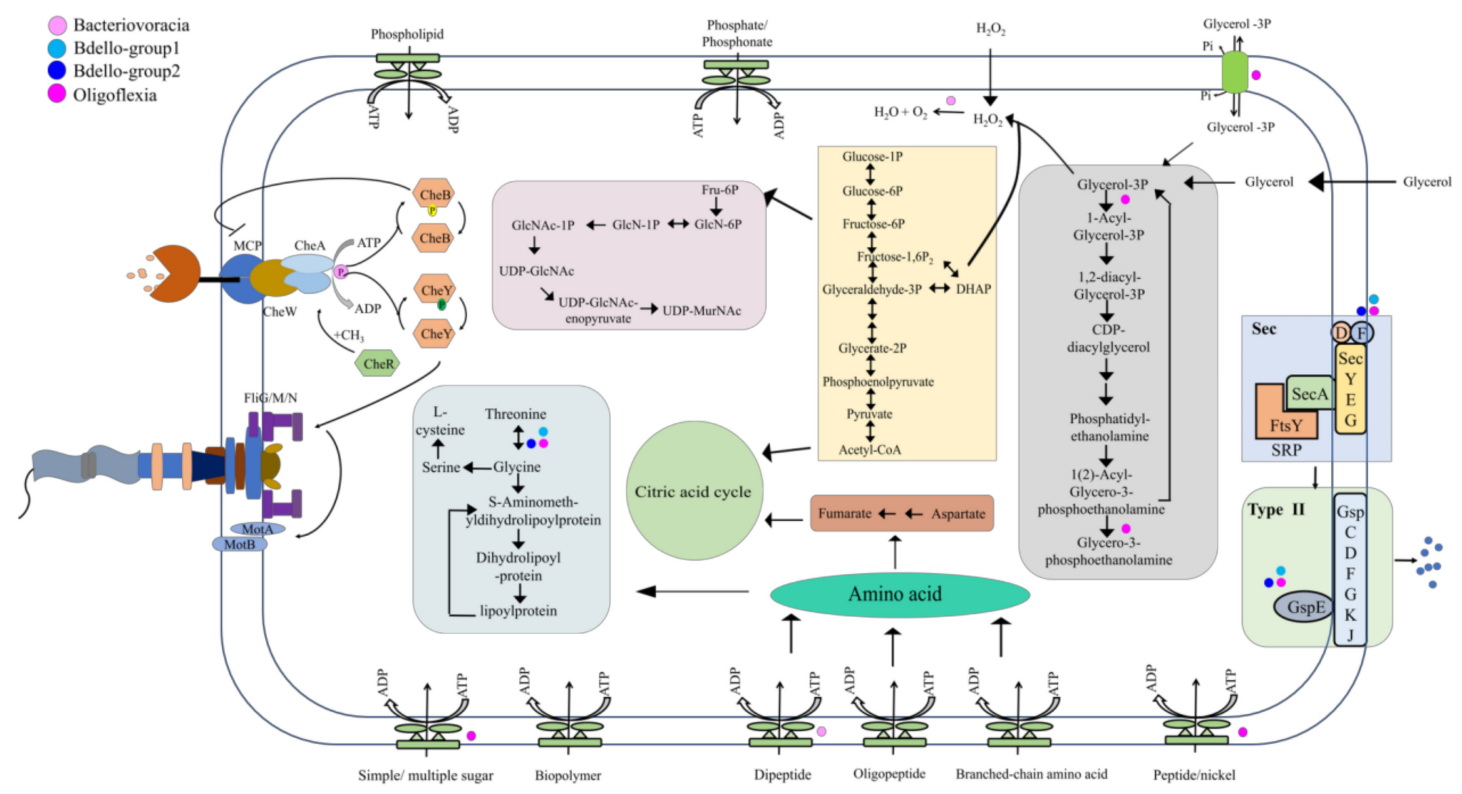

Figure 4. Metabolism reconstruction of Bdellovibrionota. The schematic metabolism and structural components of Bdellovibrionota were predicted based on KEGG annotation results for the four groups. The genes responsible for the steps without a dot are identified in all the four groups of Bdellovibrionota; if not, dots were used to denote their presence in group(s).

After invasion into periplasmatic space of prey bacteria, Bdellovibrionota bacteria begin to degrade the cytoplasmic contents of the prey cell [58]. Amino acids, glycerol and lipid of cellular components are all nutrients for Bdellovibrionota [58]. Glycerol, a simple organic molecule, can be produced by several metabolism pathways (such as glycolysis and lipid catabolism). The coding genes of glycerol kinase (GK) and glycerol-3-phospahtedehydrogenase (GLPD) were predicted in almost all Bdellovibrionota genomes (Table S6), 
which indicates that Bdellovibrionota can utilize glycerol for glycolysis (Figure 4) as reported previously [58]. The by-product of glycerol oxidation is $\mathrm{H}_{2} \mathrm{O}_{2}$, which is cytotoxic [59] and can be used to destroy cell wall structure of prey bacteria after free diffusion of $\mathrm{H}_{2} \mathrm{O}_{2}$ into the prey periplasmic space. The coding gene of sn-glycerol-3-phosphate acyltransferase (PlsB), the first enzyme for membrane phospholipid biosynthesis [60], was predicted only in Oligoflexia genomes (Table S6). This suggests that glycerol may be used for membrane phospholipid biosynthesis in rapid growth phase of Oligoflexia and thus the glycerol metabolism was diversified in Bdellovibrionota.

The metabolism reconstruction shows that there were numerous kinds of $\mathrm{ABC}$ transporters for uptake of phospholipid, lipoprotein, oligopeptide and branched-chain amino acids (Figure 4). They were also useful to import nutrients from environment in free-living phase. The strategies might help Bdellovibrionota to adapt to oligotrophic, low temperature and hydrostatic pressure in deep sea zones.

The degradation and assimilation of nutrients are essential processes during the predatory growth phase of Bdellovibrionota. When Bdellovibrionota invade the prey bacteria and entered into growth phase, the percentage of transcribed genes increased from $33 \%$ to $85 \%$ [49]. In Bdellovibrionota, amino acids derived from prey bacterial cell, environmental source and oligopeptide digestion were fed in different metabolism pathways [58]. For example, aspartate is linked with citric acid cycle and glycine may involve into lipoylprotein metabolism (Figure 4). During the release stage of Bdellovibrionota progeny, a large amount of outer cellular components was required such as peptidoglycan that is the basic unit of the cell wall [61]. Bdellovibrionota might use fructose 6-phosphate for producing uridine diphosphate (UDP)-N-acetylmuramic acid (UDP-MurNAc) (Figure 4) and subsequent biosynthesis of peptidoglycan. The Sec-type II system is almost complete in all Bdellovibrionota groups (Figure 4 and Table S5). The Type II secretion system can exude numerous bacterial toxic proteins and lytic enzymes such as proteases and lipases, which is important for bacteria to digest nutrients in the prey cell and environment [62]. Bdellovibrionota may heavily depend on their type II secretion system in the whole lifecycle. During the attack phase, the secreting proteins can probably be used to catch prey bacteria and partly destruct the outer membrane structure for entry; during the predatory growth phase, they are likely useful for cellular component digestion and complete prey cell lysis.

\subsection{Genes Involved in Survival of Bdellovibrionota in the Marine Environment}

Although many Bdellovibrionota genomes were obtained from the marine environment, there is not a special group exclusively consisting of marine species (Figure 1). Given the characteristics with high hydrostatic pressure, oligotrophy and low temperature in the deep sea, there must be some genes in Bdellovibrionota for deep-sea adaptation. To reveal these genes, we divided each group of the Bdellovibrionota genomes into two parts, non-marine and marine, according to their sample sources. The marine genomes of Bdellovibrionota mostly belonged to Bacteriovoracia and Bdello-group2 (Figure 1C). A comparison between the two groups showed that the marine genomes have bet $\mathrm{T} /$ betS genes $(77.78 \%$ of Bacteriovoracia marine genomes and $57.89 \%$ of Bdello-group 2 marine genomes) that take part in betaine biosynthesis via the choline pathway because of their high-affinity to choline (Table 2). Betaine is one of known major organic molecules that protect bacteria from damage of hypersaline/high hydrostatic pressure by stabilizing the natural conformation of proteins and preventing their aggregation [63]. Although it is reported that choline and glycine betaine are nearly ubiquitous in bacteria [63], the percentage of bet T / betS in the marine group is much higher than that in non-marine group (77.78\% vs. $21.05 \%$ of Bacteriovoracia and $57.89 \%$ vs. 0 of Bdello-group 2 ) in this study (Table 2 ). This indicates that bet $T$ / betS genes in the marine Bdellovibrionota may be critical in protecting them from the high hydrostatic pressure by importing choline/glycine/proline betaine from the sea water or the prey bacterial cells. Apart from bet $T /$ betS, the gene named mscS (Table 2), contributing to normal resistance to hypoosmotic shock, was predicted 
in $89.47 \%$ of Bdello-group2 marine genomes. The MscS channel is integrated in the cell membrane, which prevents burst of the cell in hypotonic environments [64,65]. It may work with BetT/BetS in a feedback model for maintaining and rescuing Bdellovibrionota (Bdello-group2) under the various marine chemical gradients.

Table 2. Candidate genes for adaptation to the marine environment.

\begin{tabular}{|c|c|c|c|c|}
\hline $\begin{array}{c}\text { Genes Enriched in } \\
\text { Marine Genomes of } \\
\text { Bdellovibrionota.Group }\end{array}$ & KEGG & Non-Marine & Marine & Function \\
\hline \multirow{7}{*}{ Bdello-group2 } & K03442 & $11 \%$ & $89 \%$ & \multirow{7}{*}{$\begin{array}{l}m s c S \text {; small conductance } \\
\text { mechanosensitive channel } \\
m l t A ; \text { membrane-bound lytic murein } \\
\text { transglycosylase A [EC:4.2.2.-] } \\
\text { mreD; rod shape-determining protein } \\
\text { MreD } \\
\text { bet } T \text {, betS; choline/glycine/proline betaine } \\
\text { transport protein } \\
\text { proA; glutamate-5-semialdehyde } \\
\text { dehydrogenase [EC:1.2.1.41] } \\
\text { ECM4, yqjG; glutathionyl-hydroquinone } \\
\text { reductase [EC:1.8.5.7] } \\
\text { anmK; anhydro-N-acetylmuramic acid } \\
\text { kinase [EC:2.7.1.170] }\end{array}$} \\
\hline & K08304 & $6 \%$ & $58 \%$ & \\
\hline & K03571 & $17 \%$ & $58 \%$ & \\
\hline & K02168 & $0 \%$ & $58 \%$ & \\
\hline & K00147 & $11 \%$ & $53 \%$ & \\
\hline & K07393 & $0 \%$ & $53 \%$ & \\
\hline & K09001 & $11 \%$ & $53 \%$ & \\
\hline \multirow{10}{*}{ Bdello-group1 } & K08641 & $0 \%$ & $100 \%$ & \multirow{10}{*}{$\begin{array}{l}\text { vanX; zinc D-Ala-D-Ala dipeptidase } \\
\text { [EC:3.4.13.22] } \\
\text { DPEP; membrane dipeptidase } \\
\text { [EC:3.4.13.19] } \\
\text { pepE; dipeptidase E [EC:3.4.13.21] } \\
\text { hipB; HTH-type transcriptional } \\
\text { regulator/antitoxin HipB } \\
\text { mscS; small conductance } \\
\text { mechanosensitive channel } \\
\text { betT, betS; choline/glycine/proline betaine } \\
\text { transport protein } \\
\text { relE, stbE; mRNA interferase RelE/StbE } \\
\text { hicA; mRNA interferase HicA [EC:3.1.-.-] } \\
\text { hicB; antitoxin HicB } \\
\text { parE1_3_4; toxin ParE1/3/4 }\end{array}$} \\
\hline & K01273 & $0 \%$ & $100 \%$ & \\
\hline & K05995 & $0 \%$ & $100 \%$ & \\
\hline & K15773 & $0 \%$ & $100 \%$ & \\
\hline & K03442 & $0 \%$ & $100 \%$ & \\
\hline & K02168 & $0 \%$ & $100 \%$ & \\
\hline & K06218 & $0 \%$ & $100 \%$ & \\
\hline & K07339 & $17 \%$ & $100 \%$ & \\
\hline & K18843 & $0 \%$ & $100 \%$ & \\
\hline & K19092 & $0 \%$ & $100 \%$ & \\
\hline \multirow{4}{*}{ Bacteriovoracia } & K02168 & $21 \%$ & $78 \%$ & \multirow{4}{*}{$\begin{array}{l}\text { bet } T \text {, betS; choline/glycine/proline betaine } \\
\text { transport protein } \\
\text { osm } C \text {; lipoyl-dependent peroxidase } \\
\text { cat } A \text {; chloramphenicol O-acetyltransferase } \\
\text { type A [EC:2.3.1.28] } \\
\text { katE, CAT, cat } B, \operatorname{srp} A \text {; catalase [EC:1.11.1.6] }\end{array}$} \\
\hline & K04063 & $11 \%$ & $78 \%$ & \\
\hline & K19271 & $5 \%$ & $56 \%$ & \\
\hline & K03781 & $0 \%$ & $56 \%$ & \\
\hline \multirow[t]{8}{*}{ Oligoflexia } & K01177 & $0 \%$ & $100 \%$ & \multirow{8}{*}{$\begin{array}{l}\text { beta-amylase [EC:3.2.1.2] } \\
\text { malK; multiple sugar transport system } \\
\text { ATP-binding protein [EC:3.6.3.-] } \\
\text { msmX; multiple sugar transport system } \\
\text { ATP-binding protein } \\
\text { rgpF; rhamnosyltransferase [EC:2.4.1.-] } \\
\text { sterol 3beta-glucosyltransferase } \\
\text { [EC:2.4.1.173] } \\
\text { nhaA; Na+:H+ antiporter, NhaA family } \\
\text { algI; alginate O-acetyltransferase complex } \\
\text { protein AlgI } \\
\text { CMO; choline monooxygenase } \\
\text { [EC:1.14.15.7] }\end{array}$} \\
\hline & K10111 & $0 \%$ & $100 \%$ & \\
\hline & K10112 & $0 \%$ & $100 \%$ & \\
\hline & K07272 & $0 \%$ & $100 \%$ & \\
\hline & K05841 & $0 \%$ & $100 \%$ & \\
\hline & K03313 & $0 \%$ & $100 \%$ & \\
\hline & K19294 & $0 \%$ & $100 \%$ & \\
\hline & K00499 & $0 \%$ & $100 \%$ & \\
\hline
\end{tabular}


The special physicochemical parameters of the ocean lead to diverse resistance mechanisms of marine microbes, such as detoxification. The $\mathrm{H}_{2} \mathrm{O}_{2}$ degrading genes were predicted in Bacteriovoracia marine genomes, and were perhaps involved in prevention against self-toxification of $\mathrm{H}_{2} \mathrm{O}_{2}$ induced by the byproduct of glycerol oxidation. The genes osm C (77.78\%), cat A (55.56\%) and katE (55.56\%) were present in Bacteriovoracia marine genomes (Table 2). These genes are probably related to protect cells from the toxic effects of $\mathrm{H}_{2} \mathrm{O}_{2}$ that acts as a bactericide [66]. OsmC is a protein induced by osmotic pressure [67]. Interestingly, its malfunction reduced fitness and elevated sensitivity to oxidative stress of E. coli [68]. Therefore, OsmC may participate in defense against high salinity and $\mathrm{H}_{2} \mathrm{O}_{2}$ (a defensive molecule that may also be produced by prey bacteria) in Bacteriovoracia (Figure 4). As for cat A, it was up-regulated in Streptomyces coelicolor treated with $\mathrm{H}_{2} \mathrm{O}_{2}$ during no-stationary phase and it was required for Streptomyces coelicolor growth under aerobic condition $[69,70]$. The function of kat $E$ has not yet been determined, but it is predicted to regulate the concentration of $\mathrm{H}_{2} \mathrm{O}_{2}$ [71,72]. $\mathrm{H}_{2} \mathrm{O}_{2}$ may be scavenged and degraded in Bacteriovoracia with the co-operation of OsmC, CatA and KatE for survival in deeper ocean (Figure 2 and Table 2).

In Bdello-group2 marine genomes, there are some genes involved in cell wall degradation, recycling, organization and biogenesis (Table 2). Penicillin-binding proteins are important for Bdellovibrionota to break up prey cell wall [73]. MltA encoded by 57.89\% of Bdello-group2 marine genomes is a murein degrading enzyme that is located in outermembrane and can interact with penicillin-binding protein $2[74,75]$, which is important for marine Bdello-group2 as the predator of other Gram-negative bacteria. The MreD gene was present in $57.89 \%$ of Bdello-group 2 marine genomes (Table 2) and is essential for lateral peptidoglycan synthesis [76]. We identified anmK gene in 52.63\% of Bdello-group2 marine genomes (Table 2). The enzyme encoded by anmK plays a role in cell wall recycling though transforming 1,6-anhydro-N-acetylmuramic acid (anhMurNAc) to N-acetylglucosaminephosphate (GlcNAc-P) [77]. Usually, the source of anhMurNAc is derived from its own cell wall murein [58] but, as predators, marine Bdello-group2 may reuse the component of prey bacteria for cell wall formation of the next generation. ECM4, one member of glutathione transferase that might be related to protect cell such as involved in resisting the toxicity of quinone [78], found in 52.63\% of Bdello-group2 marine genomes (Table 2) was proposed as a protein involved in cell wall biogenesis (integrity) [79]. Under deep-sea oligotrophic condition, these genes may all be associated with the whole process from murein-degrading, anhMurNAc recycling and cell wall biogenesis for proliferation of Bdello-group2 marine bacteria.

There are two genomes of Bdello-group1 (GCA_002722705.1 and GCA_002450715.1) and only one genome of Oligoflexia (R3B4) from marine. The discrepancies in genes between marine and non-marine groups were also demonstrated (Table 2). The genes involved in synthesis of osmoprotectants were also predicted in marine Bdello-group1 and Oligoflexia genomes, such as betT and $m s c S$ in Bdello-group1 and cmo in Oligoflexia (Table 2). CMO (choline monooxygenase) can catalyze the first step of glycine betaine synthesis [80], which indicates that glycine betaine can be used as an osmoprotectant in marine Oligoflexia as well. In addition, there are many genes involved in transport or transformation of sugar as osmoprotectant, such as malK, $m s m X, r g p F$ and algI genes in Oligoflexia (Table 2) [81-84]. In light of all these results, betaine as an osmoprotectant is commonly used among different groups of Bdellovibrionota, all having a variety of genes for fitness in the ocean.

\subsection{Oligoflexia as Potential Defender against Eukaryotic Pathogens}

In light of the comparison among Bdellovibrionota groups, Oligoflexia seems to be special in gene content. The chitinase gene (K01183) has many copies in Oligoflexia genomes (Figure S2), but none in other Bdellovibrionota groups. The presence of genes encoding chitinase and chitin-binding protein (Figure S2) indicates that some Oligoflexia may be able to degrade chitin $[85,86]$. The phylogenetic tree of the seven chitinases extracted 
from the Oligoflexia genomes and other species supports their close relationships with known homologs (Figure 5). To further verify the predicted ORF of the chitinases, multiple alignment was performed to validate the conserved motif 'DXXDXDXE' of chitinases (Figure 5) [87]. In addition, the Oligoflexia genomes contained a gene coding for chitinbinding protein (Figure S3 and Table S7). In addition, sec signal peptide (Sec/SPI) and lipoprotein signal peptide (Sec/SPII) were detected in the ORF of chitinase (Table S7). These results imply that some of Oligoflexia can utilize chitin in the environment as nutrient and/or attack preys with chitin ultracellular structure. In this study, the chitinase and chitin-binding protein coding genes were focused for the first time in Oligoflexia. Pathogenic fungi have chitin as a main cell wall component [88], which allows us to speculate that Oligoflexia may be used to defend against eukaryotic pathogens aside from bacterial pathogens.

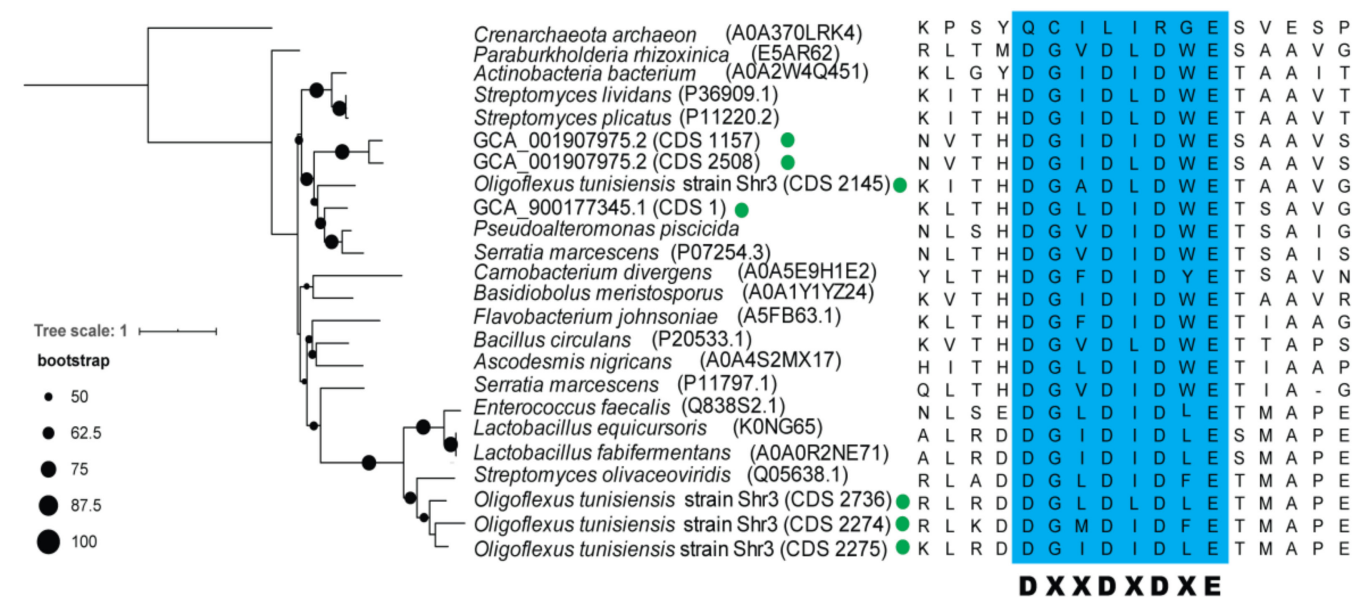

Figure 5. Phylogenetic analysis and conserved motif of chitinases from Oligoflexia. The phylogenetic tree of chitinases was built with RAxML (PROTGAMMALG model). The bootstrap values based on 1000 replicates were denoted by the size of the black dots on the branches. The Oligoflexia genomes are marked with a green dot. The conserved motif of chitinases is highlighted with blue background in the multiple sequence alignment.

\section{Discussion}

In this study, the phylogenomics of Bdellovibrionota inhabiting different niches revealed that the genomes were scattered into four groups without niche-specific groups (Figure 1A-C and Figure S1). The universal distribution of Bdellovibrionota may be due to their quick transformation in response to environmental changes [49]. Our comparison of genomic traits allows for a glance of their differences in peptidases, CAZymes, and metabolic spectrum (Figure 3B,C and Figure 4). The wide range of genome size and GC content of Bdello-group1 genomes is likely ascribed to frequent contacts with the diverse microbes in bioreactor sludges. In this study, the relative abundances of four groups of Bdellovibrionota in vertical marine water zones indicate preference of Bdellovibrionota groups to different depths. These observed distinctions may be related to the biotic (gene profiles of Bdellovibrionota, prey cell abundance and other bacterial predators) or abiotic (nutrients, temperature and hydrostatic pressure) factors in the marine environment. All the factors and predatory role of Bdellovibrionota in the control of microbial diversity need to be studied further.

Our predicted functions of the proteins responsible for the flagellar assembling, chemotaxis, and type II secretion system agree with the predatory lifestyle of Bdellovibrionota. Moreover, penicillin-binding proteins were probably important for Bdellovibrionota, because it may help Bdellovibrionota destroy the prey cell wall and invade prey cell periplasm. In addition, because of oligotrophic, low temperature and hydrostatic pressure in deep sea zones, marine Bdellovibrionota probably adapt for survival with osmoprotectant uptake, 
$\mathrm{H}_{2} \mathrm{O}_{2}$ detoxification and recycling of cell wall components. In particular, the potential capacity to reuse the cell wall and to lysis prey cell during release of Bdellovibrionota progeny is of importance to promote the circulation of geochemical elements in the deep ocean. Previous studies revealed that viral diversity at different scales affected the microbial communities in deep ocean [89]. Bacterial predators, such as Bdellovibrionota, may also influence the population size of their preys and make the microbial community more diversified in different niches as previously reported [90]. In addition, infection by MDR bacteria could be controlled with assistance of Bdellovibrionota [6]. Our result suggests that Oligoflexia seem to be potential new candidates for controlling eukaryotic pathogens, with respect to the finding of chitinase and chitin-binding protein coding genes. In addition, the presence of genes for biosynthesis of secondary molecules indicates that Oligoflexia might be candidate producers of novel biosynthetic compounds.

\section{Conclusions}

In this study, Bdellovibrionota was revealed to have four phylogenetic groups, all containing the genes in most of their genomes for two-phase predatory lifestyle. Their vertical distribution in the ocean was exhibited. Bacteriovoracia was more prevalent in the deep-sea zones. Genomics traits demonstrated that marine Bdellovibrionota were able to metabolize osmoprotectant and degrade cell wall. The chitinase and chitin-binding protein encoding genes were for the first time focused upon in Oligoflexia. However, the function and regulation of these genes involved in pathogenic prevention need to be verified by experiments.

Supplementary Materials: The following are available online at https:/ / www.mdpi.com/article/10 .3390 / microorganisms 9040757 / s1, Figure S1: Rooted phylogenetic tree of Bdellovibrionota 16S rRNA genes. Figure S2: Copy number of interested KEGG genes of Oligoflexia from different environments. Figure S3: Phylogenetic tree of chitin-binding proteins encoded by Oligoflexia genomes. Table S1: GTDB taxonomy of Bdellovibrionota genomes and MAGs from public databases. Table S2: Mediumand high-quality Bdellovibrionota genomes and MAGs. Table S3: Information of deep-sea water metagenomes. Table S4: Secondary metabolite gene clusters of Bdellovibrionota. Table S5: Genes related to lifestyle of Bdellovibrionota as predator. Table S6: KEGG annotation results. Table S7: BLASTP results of chitinase and chitin-binding protein.

Author Contributions: Y.W. and Q.-M.L. designed the study; Y.W. revised this manuscript; Q.-M.L. performed analysis of this study and wrote the manuscript; Y.-L.Z. and Z.-F.W. provided a part of scripts. All authors have read and agreed to the published version of the manuscript.

Funding: This study was supported by Key Research and Development Program of Hainan Province (E050010406) and the National Key Research and Development Program of China (2018YFC0310005 and 2016YFC0302501).

Data Availability Statement: The data presented in this study are available on request from the corresponding author.

Acknowledgments: We are grateful to the team members aboard the $R / V$ TS09, $R / V$ TAN KAH KEE cruise and $R / V$ Haigong 623 for their invaluable efforts in the collecting samples. Great thanks are given to J.L., J.C., S.X.W., Y.Z.X. and D.S.C. for their ISMIFF sampling.

Conflicts of Interest: The authors declare that there is no conflict of interest.

\section{References}

1. Stolp, H.; Starr, M. Bdellovibrio bacteriovorus gen. et sp. n., a predatory, ectoparasitic, and bacteriolytic microorganism. Antonie Van Leeuwenhoek 1963, 29, 217-248. [CrossRef]

2. Shilo, M.; Bruff, B. Lysis of Gram-Negative Bacteria by Host-Independent Ectoparasitic Bdellovibrio Bacteriovorus Isolates. J. Gen. Microbiol. 1965, 40, 317-318. [CrossRef]

3. Thomashow, M.F.; Rittenberg, S.C. Intraperiplasmic Growth of Bdellovibrio-Bacteriovorus 109j - Solubilization of Escherichia-Coli Peptidoglycan. J. Bacteriol. 1978, 135, 998-1007. [CrossRef] [PubMed]

4. Varon, M. Selection of Predation-Resistant Bacteria in Continuous Culture. Nature 1979, 277, 386-388. [CrossRef] 
5. Kadouri, D.E.; To, K.; Shanks, R.M.Q.; Doi, Y. Predatory Bacteria: A Potential Ally against Multidrug-Resistant Gram-Negative Pathogens. PLoS ONE 2013, 8, e63397. [CrossRef] [PubMed]

6. Shatzkes, K.; Singleton, E.; Tang, C.; Zuena, M.; Shukla, S.; Gupta, S.; Dharani, S.; Onyile, O.; Rinaggio, J.; Connell, N.D.; et al. Predatory Bacteria Attenuate Klebsiella pneumoniae Burden in Rat Lungs. mBio 2016, 7, 279-282. [CrossRef] [PubMed]

7. Cai, J.; Cao, Q. New Bdellovibrio species mutant strain BDE-1F2 used for lysing pathogenic and/or potentially pathogenic bacteria associated with aquaculture, preferably Gram-negative and/or positive pathogenic bacteria e.g. Enterococcus. Univ. South China Technol. Patent number, CN111363689-A, 2020.

8. Chaumeil, P.A.; Mussig, A.J.; Hugenholtz, P.; Parks, D.H. GTDB-Tk: A toolkit to classify genomes with the Genome Taxonomy Database. Bioinformatics 2020, 36, 1925-1927. [CrossRef]

9. Jurkevitch, E.; Minz, D.; Ramati, B.; Barel, G. Prey range characterization, ribotyping, and diversity of soil and rhizosphere Bdellovibrio spp. isolated on phytopathogenic bacteria. Appl. Environ. Microb. 2000, 66, 2365-2371. [CrossRef]

10. Sockett, R.E. Predatory Lifestyle of Bdellovibrio bacteriovorus. Annu. Rev. Microbiol. 2009, 63, 523-539. [CrossRef]

11. Hobley, L.; Lerner, T.R.; Williams, L.E.; Lambert, C.; Till, R.; Milner, D.S.; Basford, S.M.; Capeness, M.J.; Fenton, A.K.; Atterbury, R.J.; et al. Genome analysis of a simultaneously predatory and prey-independent, novel Bdellovibrio bacteriovorus from the River Tiber, supports in silico predictions of both ancient and recent lateral gene transfer from diverse bacteria. BMC Genom. 2012, 13, 670. [CrossRef] [PubMed]

12. Paix, B.; Ezzedine, J.A.; Jacquet, S. Diversity, Dynamics, and Distribution of Bdellovibrio and Like Organisms in Perialpine Lakes. Appl. Environ. Microbio. 2019, 85, e02494-18. [CrossRef]

13. Koval, S.F.; Hynes, S.H.; Flannagan, R.S.; Pasternak, Z.; Davidov, Y.; Jurkevitch, E. Bdellovibrio exovorus sp nov., a novel predator of Caulobacter crescentus. Int. J. Syst. Evol. Micr. 2013, 63, 146-151. [CrossRef] [PubMed]

14. Bratanis, E.; Andersson, T.; Lood, R.; Bukowska-Faniband, E. Biotechnological Potential of Bdellovibrio and Like Organisms and Their Secreted Enzymes. Front. Microbiol. 2020, 11, 662. [CrossRef]

15. Zhou, Z.C.; Tran, P.Q.; Kieft, K.; Anantharaman, K. Genome diversification in globally distributed novel marine Proteobacteria is linked to environmental adaptation. ISME J. 2020, 14, 2060-2077. [CrossRef]

16. Williams, H.N.; Lymperopoulou, D.S.; Athar, R.; Chauhan, A.; Dickerson, T.L.; Chen, H.; Laws, E.; Berhane, T.K.; Flowers, A.R.; Bradley, N.; et al. Halobacteriovorax, an underestimated predator on bacteria: Potential impact relative to viruses on bacterial mortality. ISME J. 2016, 10, 491-499. [CrossRef]

17. Nazarenko, E.L.; Crawford, R.J.; Ivanova, E.P. The Structural Diversity of Carbohydrate Antigens of Selected Gram-Negative Marine Bacteria. Mar. Drugs 2011, 9, 1914-1954. [CrossRef]

18. Hibbing, M.E.; Fuqua, C.; Parsek, M.R.; Peterson, S.B. Bacterial competition: surviving and thriving in the microbial jungle. Nat. Rev. Microbiol. 2010, 8, 15-25. [CrossRef] [PubMed]

19. Parks, D.H.; Imelfort, M.; Skennerton, C.T.; Hugenholtz, P.; Tyson, G.W. CheckM: assessing the quality of microbial genomes recovered from isolates, single cells, and metagenomes. Genome Res. 2015, 25, 1043-1055. [CrossRef]

20. Wang, Y.; Gao, Z.M.; Li, J.; He, L.S.; Cui, G.J.; Li, W.L.; Chen, J.; Xin, Y.Z.; Cai, D.S.; Zhang, A.Q. Hadal water sampling by in situ microbial filtration and fixation (ISMIFF) apparatus. Deep Sea Res. Part I-Oceanogr. Res. Pap. 2019, 144, 132-137. [CrossRef]

21. Andrews, S. FastQC: A Quality Control Tool for High Throughput Sequence Data. 2010. Available online: https://www. bioinformatics.babraham.ac.uk/projects/fastqc/ (accessed on 8 January 2019).

22. Chen, S.; Zhou, Y.; Chen, Y.; Gu, J. Fastp: An ultra-fast all-in-one FASTQ preprocessor. Bioinformatics 2018, 34, i884-i890. [CrossRef] [PubMed]

23. Xu, H.; Luo, X.; Qian, J.; Pang, X.; Song, J.; Qian, G.; Chen, J.; Chen, S. FastUniq: A fast de novo duplicates removal tool for paired short reads. PLoS ONE 2012, 7, e52249. [CrossRef] [PubMed]

24. Li, D.; Liu, C.M.; Luo, R.; Sadakane, K.; Lam, T.W. MEGAHIT: An ultra-fast single-node solution for large and complex metagenomics assembly via succinct de Bruijn graph. Bioinformatics 2015, 31, 1674-1676. [CrossRef]

25. Uritskiy, G.V.; DiRuggiero, J.; Taylor, J. MetaWRAP-a flexible pipeline for genome-resolved metagenomic data analysis. Microbiome 2018, 6, 158. [CrossRef] [PubMed]

26. Huang, Y.; Gilna, P.; Li, W. Identification of ribosomal RNA genes in metagenomic fragments. Bioinformatics 2009, 25, 1338-1340. [CrossRef] [PubMed]

27. Sunagawa, S.; Coelho, L.P.; Chaffron, S.; Kultima, J.R.; Labadie, K.; Salazar, G.; Djahanschiri, B.; Zeller, G.; Mende, D.R.; Alberti, A.; et al. Structure and function of the global ocean microbiome. Science 2015, 348, 1261359. [CrossRef] [PubMed]

28. Gao, Z.M.; Huang, J.M.; Cui, G.J.; Li, W.L.; Li, J.; Wei, Z.F.; Chen, J.; Xin, Y.Z.; Cai, D.S.; Zhang, A.Q.; et al. In situ meta-omic insights into the community compositions and ecological roles of hadal microbes in the Mariana Trench. Environ. Microbiol. 2019, 21, 4092-4108. [CrossRef]

29. Li, W.L.; Huang, J.M.; Zhang, P.W.; Cui, G.J.; Wei, Z.F.; Wu, Y.Z.; Gao, Z.M.; Han, Z.; Wang, Y. Periodic and Spatial Spreading of Alkanes and Alcanivorax Bacteria in Deep Waters of the Mariana Trench. Appl. Appl. Environ. Microbiol. 2019, 85, e02089-18. [CrossRef] [PubMed]

30. Altschul, S.F.; Gish, W.; Miller, W.; Myers, E.W.; Lipman, D.J. Basic local alignment search tool. J. Mol. Biol. 1990, 215 , 403-410. [CrossRef]

31. Hyatt, D.; Chen, G.L.; Locascio, P.F.; Land, M.L.; Larimer, F.W.; Hauser, L.J. Prodigal: Prokaryotic gene recognition and translation initiation site identification. BMC Bioinform. 2010, 11, 119. [CrossRef] 
32. Aramaki, T.; Blanc-Mathieu, R.; Endo, H.; Ohkubo, K.; Kanehisa, M.; Goto, S.; Ogata, H. KofamKOALA: KEGG Ortholog assignment based on profile HMM and adaptive score threshold. Bioinformatics 2020, 36, 2251-2252. [CrossRef]

33. Kanehisa, M.; Goto, S. KEGG: Kyoto Encyclopedia of Genes and Genomes. Nucleic Acids Res. 2000, 28, 27-30. [CrossRef]

34. Gish, W.; States, D.J. Identification of protein coding regions by database similarity search. Nat. Genet. 1993, 3, 266-272. [CrossRef]

35. Tatusov, R.L.; Galperin, M.Y.; Natale, D.A.; Koonin, E.V. The COG database: A tool for genome-scale analysis of protein functions and evolution. Nucleic Acids Res. 2000, 28, 33-36. [CrossRef] [PubMed]

36. Eddy, S.R. Multiple Alignment Using Hidden Markov Models. Third Int. Conf. Intel. Syst. Mol. Biol. 1995, 3, 114-120. [CrossRef]

37. Lombard, V.; Ramulu, H.G.; Drula, E.; Coutinho, P.M.; Henrissat, B. The carbohydrate-active enzymes database (CAZy) in 2013. Nucleic Acids Res. 2014, 42, D490-D495. [CrossRef] [PubMed]

38. Rawlings, N.D.; Alan, J.; Thomas, P.D.; Huang, X.D.; Bateman, A.; Finn, R.D. The MEROPS database of proteolytic enzymes, their substrates and inhibitors in 2017 and a comparison with peptidases in the PANTHER database. Nucleic Acids Res. 2018, 46, D624-D632. [CrossRef]

39. Blin, K.; Wolf, T.; Chevrette, M.G.; Lu, X.; Schwalen, C.J.; Kautsar, S.A.; Suarez Duran, H.G.; de Los Santos, E.L.C.; Kim, H.U.; Nave, M.; et al. antiSMASH 4.0-improvements in chemistry prediction and gene cluster boundary identification. Nucleic Acids Res. 2017, 45, W36-W41. [CrossRef]

40. Medema, M.H.; Kottmann, R.; Yilmaz, P.; Cummings, M.; Biggins, J.B.; Blin, K.; de Bruijn, I.; Chooi, Y.H.; Claesen, J.; Coates, R.C.; et al. Minimum Information about a Biosynthetic Gene cluster. Nat. Chem. Biol. 2015, 11, 625-631. [CrossRef]

41. Zhang, W.; Ding, W.; Li, Y.X.; Tam, C.; Bougouffa, S.; Wang, R.; Pei, B.; Chiang, H.; Leung, P.; Lu, Y.; et al. Marine biofilms constitute a bank of hidden microbial diversity and functional potential. Nat. Commun. 2019, 10, 517. [CrossRef]

42. Tully, B.J. Metabolic diversity within the globally abundant Marine Group II Euryarchaea offers insight into ecological patterns. Nat. Commun. 2019, 10, 271. [CrossRef]

43. Stamatakis, A. RAxML version 8: A tool for phylogenetic analysis and post-analysis of large phylogenies. Bioinformatics 2014, 30, 1312-1313. [CrossRef]

44. Capella-Gutierrez, S.; Silla-Martinez, J.M.; Gabaldon, T. trimAl: A tool for automated alignment trimming in large-scale phylogenetic analyses. Bioinformatics 2009, 25, 1972-1973. [CrossRef]

45. Fu, L.; Niu, B.; Zhu, Z.; Wu, S.; Li, W. CD-HIT: Accelerated for clustering the next-generation sequencing data. Bioinformatics 2012, 28, 3150-3152. [CrossRef]

46. Katoh, K.; Standley, D.M. MAFFT multiple sequence alignment software version 7: Improvements in performance and usability. Mol. Biol. Evol. 2013, 30, 772-780. [CrossRef]

47. Letunic, I.; Bork, P. Interactive Tree Of Life (iTOL): An online tool for phylogenetic tree display and annotation. Bioinformatics 2007, 23, 127-128. [CrossRef] [PubMed]

48. Im, H.; Kwon, H.; Cho, G.; Kwon, J.; Choi, S.Y.; Mitchell, R.J. Viscosity has dichotomous effects on Bdellovibrio bacteriovorus HD100 predation. Environ. Microbiol. 2019, 21, 4675-4684. [CrossRef] [PubMed]

49. Karunker, I.; Rotem, O.; Dori-Bachash, M.; Jurkevitch, E.; Sorek, R. A Global Transcriptional Switch between the Attack and Growth Forms of Bdellovibrio bacteriovorus. PLoS ONE 2013, 8, e61850. [CrossRef]

50. Nguyen, T.T.H.; Myrold, D.D.; Mueller, R.S. Distributions of Extracellular Peptidases Across Prokaryotic Genomes Reflect Phylogeny and Habitat. Front. Microbiol. 2019, 10, 413. [CrossRef] [PubMed]

51. Schmid, J.; Heider, D.; Wendel, N.J.; Sperl, N.; Sieber, V. Bacterial Glycosyltransferases: Challenges and Opportunities of a Highly Diverse Enzyme Class Toward Tailoring Natural Products. Front. Microbiol. 2016, 7, 182. [CrossRef] [PubMed]

52. Straley, S.C.; Lamarre, A.G.; Lawrence, L.J.; Conti, S.F. Chemotaxis of Bdellovibrio-Bacteriovorus toward Pure Compounds. J. Bacteriol. 1979, 140, 634-642. [CrossRef] [PubMed]

53. Suzuki, Y.; Morimoto, Y.V.; Oono, K.; Hayashi, F.; Oosawa, K.; Kudo, S.; Nakamura, S. Effect of the MotA(M206I) Mutation on Torque Generation and Stator Assembly in the Salmonella H+-Driven Flagellar Motor. J. Bacteriol. 2019, 201, e00727-18. [CrossRef]

54. Lambert, C.; Smith, M.C.; Sockett, R.E. A novel assay to monitor predator-prey interactions for Bdellovibrio bacteriovorus $109 \mathrm{~J}$ reveals a role for methyl-accepting chemotaxis proteins in predation. Environ. Microbiol. 2003, 5, 127-132. [CrossRef]

55. Kehry, M.R.; Bond, M.W.; Hunkapiller, M.W.; Dahlquist, F.W. Enzymatic damidation of methyl-accpting chem otaxis proteins in Escherichia coli catalyzed by the cheB gene prouct. Proc. Natl. Acad. Sci. USA 1983, 80, 3599-3603. [CrossRef] [PubMed]

56. Batra, M.; Sharma, R.; Chandra, V.; Aggarwal, M.; Agarwal, U.; Gupta, P.; Singh, R.P.; Tomar, S. In silico and proteomic analysis of protein methyltransferase CheR from Bacillus subtilis. Int. J. Biol. Macromol. 2015, 77, 168-180. [CrossRef]

57. Hamadeh, A.; Roberts, M.A.J.; August, E.; McSharry, P.E.; Maini, P.K.; Armitage, J.P.; Papachristodoulou, A. Feedback Control Architecture and the Bacterial Chemotaxis Network. PLoS Comput. Biol. 2011, 7, e1001130. [CrossRef] [PubMed]

58. Ruby, E.G.; McCabe, J.B. Metabolism of periplasmic membrane-derived oligosaccharides by the predatory bacterium Bdellovibrio bacteriovorus 109J. J. Bacteriol. 1988, 170, 646-652. [CrossRef]

59. Wang, Y.; Huang, J.M.; Zhou, Y.L.; Almeida, A.; Finn, R.D.; Danchin, A.; He, L.S. Phylogenomics of expanding uncultured environmental Tenericutes provides insights into their pathogenicity and evolutionary relationship with Bacilli. BMC Genom. 2020, 21, 408. [CrossRef] [PubMed]

60. Feng, Y.J.; Cronan, J.E. The Vibrio cholerae fatty acid regulatory protein, FadR, represses transcription of plsB, the gene encoding the first enzyme of membrane phospholipid biosynthesis. Mol. Microbiol. 2011, 81, 1020-1033. [CrossRef] [PubMed] 
61. Typas, A.; Banzhaf, M.; Gross, C.A.; Vollmer, W. From the regulation of peptidoglycan synthesis to bacterial growth and morphology. Nat. Rev. Microbiol. 2012, 10, 123-136. [CrossRef] [PubMed]

62. Korotkov, K.V.; Sandkvist, M.; Hol, W.G.J. The type II secretion system: Biogenesis, molecular architecture and mechanism. Nat. Rev. Microbiol. 2012, 10, 336-351. [CrossRef] [PubMed]

63. Nieder, J.B.; Hussels, M.; Bittl, R.; Brecht, M. Effect of TMAO and betaine on the energy landscape of photosystem I. Bba-Bioenergetics 2014, 1837, 849-856. [CrossRef] [PubMed]

64. Booth, I.R.; Blount, P. The MscS and MscL Families of Mechanosensitive Channels Act as Microbial Emergency Release Valves. J. Bacteriol. 2012, 194, 4802-4809. [CrossRef] [PubMed]

65. Bialecka-Fornal, M.; Lee, H.J.; Phillips, R. The Rate of Osmotic Downshock Determines the Survival Probability of Bacterial Mechanosensitive Channel Mutants. J. Bacteriol. 2015, 197, 231-237. [CrossRef] [PubMed]

66. Armoza-Zvuloni, R.; Schneider, A.; Shaked, Y. Rapid Hydrogen Peroxide Release during Coral-Bacteria Interactions. Front. Mar. Sci. 2016, 3, 124. [CrossRef]

67. Gutierrez, C.; Devedjian, J.C. Osmotic Induction of Gene Osmc Expression in Escherichia-Coli K12. J. Mol. Biol. 1991, 220, 959-973. [CrossRef]

68. Conter, A.; Gangneux, C.; Suzanne, M.; Gutierrez, C. Survival of Escherichia coli during long-term starvation: Effects of aeration, $\mathrm{NaCl}$, and the rpoS and osmC gene products. Res. Microbiol. 2001, 152, 17-26. [CrossRef]

69. Cho, Y.H.; Roe, J.H. Isolation and expression of the catA gene encoding the major vegetative catalase in Streptomyces coelicolor Muller. J. Bacteriol. 1997, 179, 4049-4052. [CrossRef] [PubMed]

70. Hahn, J.S.; Oh, S.Y.; Chater, K.F.; Cho, Y.H.; Roe, J.H. H2O2-sensitive fur-like repressor CatR regulating the major catalase gene in Streptomyces coelicolor. J. Biol. Chem. 2000, 275, 38254-38260. [CrossRef]

71. Sun, D.; Crowell, S.A.; Harding, C.M.; De Silva, P.M.; Harrison, A.; Fernando, D.M.; Mason, K.M.; Santana, E.; Loewen, P.C.; Kumar, A.; et al. KatG and KatE confer Acinetobacter resistance to hydrogen peroxide but sensitize bacteria to killing by phagocytic respiratory burst. Life Sci. 2016, 148, 31-40. [CrossRef]

72. Rochat, T.; Miyoshi, A.; Gratadoux, J.J.; Duwat, P.; Sourice, S.; Azevedo, V.; Langella, P. High-level resistance to oxidative stress in Lactococcus lactis conferred by Bacillus subtilis catalase KatE. Microbiology 2005, 151, 3011-3018. [CrossRef]

73. Lerner, T.R.; Lovering, A.L.; Bui, N.K.; Uchida, K.; Aizawa, S.; Vollmer, W.; Sockett, R.E. Specialized peptidoglycan hydrolases sculpt the intra-bacterial niche of predatory Bdellovibrio and increase population fitness. PLoS Pathog. 2012, 8, e1002524. [CrossRef]

74. Lommatzsch, J.; Templin, M.F.; Kraft, A.R.; Vollmer, W.; Holtje, J.V. Outer membrane localization of murein hydrolases: MltA, a third lipoprotein lytic transglycosylase in Escherichia coli. J. Bacteriol. 1997, 179, 5465-5470. [CrossRef]

75. Jennings, G.T.; Savino, S.; Marchetti, E.; Arico, B.; Kast, T.; Baldi, L.; Ursinus, A.; Holtje, J.V.; Nicholas, R.A.; Rappuoli, R.; et al. GNA33 from Neisseria meningitidis serogroup B encodes a membrane-bound lytic transglycosylase (MltA). Eur. J. Biochem. 2002, 269, 3722-3731. [CrossRef] [PubMed]

76. White, C.L.; Kitich, A.; Gober, J.W. Positioning cell wall synthetic complexes by the bacterial morphogenetic proteins MreB and MreD. Mol. Microbiol. 2010, 76, 616-633. [CrossRef] [PubMed]

77. Uehara, T.; Suefuji, K.; Valbuena, N.; Meehan, B.; Donegan, M.; Park, J.T. Recycling of the anhydro-N-acetylmuramic acid derived from cell wall murein involves a two-step conversion to N-acetylglucosamine-phosphate. J. Bacteriol. 2005, 187, 3643-3649. [CrossRef] [PubMed]

78. Schwartz, M.; Didierjean, C.; Hecker, A.; Girardet, J.M.; Morel-Rouhier, M.; Gelhaye, E.; Favier, F. Crystal Structure of Saccharomyces cerevisiae ECM4, a Xi-Class Glutathione Transferase that Reacts with Glutathionyl-(hydro)quinones. PLoS ONE 2016, 11, e0164678. [CrossRef]

79. Teixeira, M.C.; Fernandes, A.R.; Mira, N.P.; Becker, J.D.; Sa-Correia, I. Early transcriptional response of Saccharomyces cerevisiae to stress imposed by the herbicide 2,4-dichlorophenoxyacetic acid. FEMS Yeast Res. 2006, 6, 230-248. [CrossRef]

80. Luo, D.; Niu, X.; Yu, J.; Yan, J.; Gou, X.; Lu, B.R.; Liu, Y. Rice choline monooxygenase (OsCMO) protein functions in enhancing glycine betaine biosynthesis in transgenic tobacco but does not accumulate in rice (Oryza sativa L. ssp. japonica). Plant Cell Rep. 2012, 31, 1625-1635. [CrossRef]

81. Diederichs, K.; Diez, J.; Greller, G.; Muller, C.; Breed, J.; Schnell, C.; Vonrhein, C.; Boos, W.; Welte, W. Crystal structure of MalK, the ATPase subunit of the trehalose/maltose ABC transporter of the archaeon Thermococcus litoralis. EMBO J. 2000, 19, 5951-5961. [CrossRef]

82. Ferreira, M.J.; de Sa-Nogueira, I. A Multitask ATPase Serving Different ABC-Type Sugar Importers in Bacillus subtilis. J. Bacteriol. 2010, 192, 5312-5318. [CrossRef] [PubMed]

83. Kovacs, C.J.; Faustoferri, R.C.; Quivey, R.G. RgpF Is Required for Maintenance of Stress Tolerance and Virulence in Streptococcus mutans. J. Bacteriol. 2017, 199. [CrossRef]

84. Jang, C.H.; Piao, Y.L.; Huang, X.Q.; Yoon, E.J.; Park, S.H.; Lee, K.; Zhan, C.G.; Cho, H. Modeling and Re-Engineering of Azotobacter vinelandii Alginate Lyase to Enhance Its Catalytic Efficiency for Accelerating Biofilm Degradation. PLoS ONE 2016, 11, e0156197. [CrossRef] [PubMed]

85. Frederiksen, R.F.; Paspaliari, D.K.; Larsen, T.; Storgaard, B.G.; Larsen, M.H.; Ingmer, H.; Palcic, M.M.; Leisner, J.J. Bacterial chitinases and chitin-binding proteins as virulence factors. Microbiol-Sgm 2013, 159, 833-847. [CrossRef] 
86. Tran, H.T.; Barnich, N.; Mizoguchi, E. Potential role of chitinases and chitin-binding proteins in host-microbial interactions during the development of intestinal inflammation. Histopathololgy 2011, 26, 1453-1464. [CrossRef]

87. Tyler, L.; Bragg, J.N.; Wu, J.J.; Yang, X.H.; Tuskan, G.A.; Vogel, J.P. Annotation and comparative analysis of the glycoside hydrolase genes in Brachypodium distachyon. BMC Genom. 2010, 11, 600. [CrossRef] [PubMed]

88. Lenardon, M.D.; Munro, C.A.; Gow, N.A. Chitin synthesis and fungal pathogenesis. Curr. Opin. Microbiol. 2010, 13, 416-423. [CrossRef]

89. Gregory, A.C.; Zayed, A.A.; Conceicao-Neto, N.; Temperton, B.; Bolduc, B.; Alberti, A.; Ardyna, M.; Arkhipova, K.; Carmichael, M.; Cruaud, C.; et al. Marine DNA Viral Macro- and Microdiversity from Pole to Pole. Cell 2019, 177, 1109-1123. [CrossRef]

90. Johnke, J.; Fraune, S.; Bosch, T.C.G.; Hentschel, U.; Schulenburg, H. Bdellovibrio and Like Organisms Are Predictors of Microbiome Diversity in Distinct Host Groups. Microbiol. Ecol. 2020, 79, 252-257. [CrossRef] 